\section{Changes in Family Physicians' Perceptions of Electronic Cigarettes in Tobacco Use Counseling Between 2016 and 2019}

Samuel Ofei-Dodoo, Ph.D., MPA, M.A.,2, Jennifer Wipperman, M.D., MPH ${ }^{1,2}$, Ruth Nutting, Ph.D., ${ }^{1,2}$, Karissa Gilchrist, M.D. ${ }^{2}$, Rick Kellerman, M.D. ${ }^{1}$

University of Kansas School of Medicine-Wichita, Wichita, KS 'Department of Family and Community Medicine

${ }^{2}$ Family Medicine Residency Program at Ascension Via Christi Hospitals

Received July 10, 2020; Accepted for publication Sept. 10, 2020; Published online Dec: 11, 2020 htlps: / doi.org 10.17161 lijm.voll3.13877

\section{ABSTRACT}

Introduction. Given the recent reports of e-cigarette, or vaping, product use-associated lung injury (EVALI) and harm of e-cigarettes, the authors evaluated changes in the use and perception of e-cigarettes as tobacco use cessation tools in 2019 relative to 2016. The authors also evaluated the sources family physicians most commonly use to receive information regarding e-cigarettes.

Methods. A cross-sectional online survey of 248 community family physicians in Kansas was conducted from October 2019 to December 2019. An 11-item questionnaire measured the participants' perceptions of recommending e-cigarettes to patients for tobacco cessation. A mixed method approach was used to collect, analyze, and interpret the data. Standard descriptive statistics, Likelihood-Ratio/Fisher's exact tests, and immersion-crystallization methods were used to analyze the data.

Results. The response rate was 59.3\% (147/248). The proportion of the family physicians who did not recommend e-cigarettes for tobacco use cessation was significantly higher in 2019 than in 2016 ( $86 \%$ vs. $\left.82 \% ; \chi^{2}[1, \mathrm{n}=261]=12.31 ; \mathrm{p}<0.01\right)$. Several reasons regarding respondents' perceptions of e-cigarettes as tobacco use cessation tools were reported. The medical literature and news media were the top sources where family physicians accessed e-cigarettes information.

Conclusion. Most family physicians did not recommend e-cigarettes for tobacco cessation. Opinions regarding the efficacy and safety of e-cigarettes were influenced by information sources. Future, larger studies would be beneficial to further determine family physicians' beliefs and practices regarding e-cigarettes as tobacco use cessation products. Kans J Med 2020;13:311-317

\section{INTRODUCTION}

In August 2019, the U.S. Centers for Disease Control and Prevention (CDC) reported that it was investigating more than 215 cases of severe lung illness and the possible link with electronic cigarette (e-cigarette) products in 25 states. ${ }^{1,2}$ Subsequently, several case series reported lung injury associated with vaping ranging from pneumonia to acute respiratory distress syndrome requiring mechanical ventilation. ${ }^{3}$ A reported 2,807 e-cigarette, or vaping, product use-associated lung injury (EVALI)-related cases were reported from all 50 states, as well as the District of Columbia, and two U.S. territories (Puerto Rico and U.S. Virgin Islands), with 68 deaths. ${ }^{4}$ Publications in the lay press have called attention to the impact of vaping on teens and young This is an open-access article distributed under the terms of the Creative Commons Attribution Non-C org/licenses/by-nc-nd/4.0/)

\section{KANSAS JOURNAL of MEDICINE}

adults, increasing public awareness of vaping-related lung illnesses. ${ }^{5-8}$

As reports of harm associated with vaping rise and as efficacy of tobacco use cessation with e-cigarettes remains uncertain, the debate on the use of e-cigarettes as a tobacco use cessation strategy continues. $^{9-11}$ This study was conducted to evaluate if the 2019 outbreak of EVALI and resultant medical and media reports were associated with a change in family physicians' perceptions of e-cigarettes as tobacco use cessation tools. Family physicians' perception of e-cigarettes for tobacco use cessation were first reported in 2017. ${ }^{12}$ Here, results of a follow-up 2019 survey are presented to evaluate changes in the perception of e-cigarettes as tobacco use cessation products with comparison to 2016 findings. The sources family physicians most commonly used to receive information regarding e-cigarettes also were evaluated.

\section{METHODS}

Study Design. This study was a cross-sectional survey of Kansas family physicians in active practice. The 2019 survey used methods similar to those of the study published in $2017,{ }^{12}$ a mixed methods approach to collect, analyze, and interpret the data. ${ }^{13}$ The quantitative approach allowed the authors to obtain value-free and objective insights into the respondents' opinions about e-cigarettes, while the qualitative approach allowed for an in-depth understanding of those insights. Community-based family physicians were surveyed as well as faculty and resident physicians of the three family medicine residencies sponsored by the University of Kansas School of Medicine-Wichita (KUSMW) Department of Family and Community Medicine (DFCM). The questionnaire focused on physician perceptions of recommending e-cigarettes for tobacco cessation. The KUSM-W Institutional Review Board granted exemption for the study as non-human subject research.

Study Instrument and Data Collection Process. An 1l-item questionnaire (Appendix A) similar to what was used in the 2017 study, measured family physicians' perceptions of recommending e-cigarettes to patients for tobacco cessation. ${ }^{12}$ The survey questionnaire was hosted

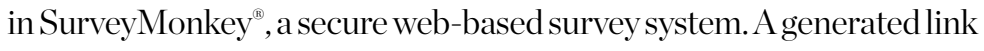
to the survey was sent via email to potential participants. The DFCM used an email system called FM-RADIO (Family Medicine Research and Data Information Office) as a survey collection tool. The FMRADIO is an electronic practice-based research network comprised of family physicians throughout the State of Kansas who are KUSM-W Family Medicine Residency program graduates, actively practicing family physician non-graduates, faculty physicians, and resident physicians. The link initially was sent to 248 community physicians, faculty physicians, and resident physicians who were on the FM RADIO list. Two reminders subsequently were sent to those who had not completed the survey. The data were collected from October 2019 to December 2019.

Data Analyses. Standard descriptive statistics were used to create a demographic profile of the respondents. Associations between the variables, as well as comparison between the proportion of family 
KANSAS JOURNAL of MEDICINE PERCEPTIONS OF E-CIGARETTES INTOBACCO USE COUNSELING

continued.

physicians who recommended e-cigarettes as tobacco use cessation products in 2016 and 2019, were evaluated using a Likelihood-Ratio test. The Likelihood-Ratio test evaluated the relationship between the family physicians' decisions to recommend e-cigarettes as tobacco use cessation products and the sources where they commonly obtained information regarding e-cigarettes. The respondents' perceived effectiveness of e-cigarettes was clustered into three groups (ineffective [combination of very ineffective and ineffective], neither ineffective nor effective, and effective [combination of very effective and effective]) and compared between the two time periods (2016 and 2019) using a Fisher's exact test. The Fisher's exact test was used in cases where the expected numbers were small.

The study team used an immersion-crystallization approach ${ }^{13-15}$ to analyze the content of respondents' qualitative data (open-ended responses) individually and in a group meeting. Immersion-crystallization is a process where researchers examine collected data in detail and periodically suspend the immersion process to reflect on emerging findings until consistent themes are identified. ${ }^{13,15}$ This multidisciplinary team was composed of a health psychologist (SO-D), two family physicians (RK, JW), a behavioral scientist $(\mathrm{RN})$, and a family medicine resident (KG). All quantitative analyses were performed with a two-sided alpha of 0.05 using IBM SPSS (Statistical Package for the Social Sciences) package, version 26.

\section{RESULTS}

Participant Characteristics. Of the 248 potential participants, data were collected from 147, a $59.3 \%$ response rate. As shown in Table 1, the demographic characteristics of the 2019 respondents were statistically different from those of the 2016 survey in age ( $p=$ $0.007)$, career status $(p<0.001)$, years in practice $(p=0.004)$, and years as a full-time faculty physician $(\mathrm{p}=0.040)$. There was no statistical difference between the two cohorts in terms of sex.

Quantitative Results. The proportion of the family physicians who did not recommend e-cigarettes for tobacco use cessation was significantly higher in 2019 than in 2016 (86\% vs. $82 \% ; \chi^{2}[1, \mathrm{n}=261]$ $=12.31 ; \mathrm{p}<0.01)$, and respondents listed several reasons for their decisions. The physicians' career status (community-based physicians, full-time faculty physicians, and resident-physicians) and decision to recommend e-cigarettes (yes or no) were found to be not significantly related $\left(\chi^{2}[2, \mathrm{n}=140]=2.52 ; \mathrm{p}>0.05\right)$. The percentages of community-based physicians, full-time faculty physicians, and resident-physicians were $87.3 \%, 77.4 \%$, and $89.9 \%$, respectively.

Family physicians were asked where they most commonly received information about adverse effects of e-cigarettes. Of 137 respondents, $45.3 \%$ received information from medical literature, $37.2 \%$ from news media, $8.0 \%$ from colleagues, $3.6 \%$ from social media, and $5.8 \%$ from other sources, including the American Academy of Family Physicians (AAFP) SmartBrief e-newsletter, AAFP and/or the American Medical Association (AMA) newsletters, and the U.S. Centers for Disease Control and Prevention (CDC) website. These sources of information were grouped into three clusters (medical literature, news media, and all other sources [combination of colleagues, social media, other professional organizations]). The reason for the grouping of all other sources was the relatively low number of respondents who used these individual methods of accessing information.

Table 1. Demographic profile of participants.

\begin{tabular}{|c|c|c|c|}
\hline Characteristics & $\begin{array}{l}2019 \text { Respondents } \\
(\mathrm{N}=147)\end{array}$ & $\begin{array}{l}2016 \text { Respondents } \\
(\mathrm{N}=117)\end{array}$ & p value \\
\hline \multicolumn{4}{|l|}{ Sex, no. $(\%)$} \\
\hline Male & $77(55.4)$ & $57(53.3)$ & \\
\hline Female & $62(44.6)$ & $50(46.7)$ & \\
\hline Missing* $^{*}$ & 8 & 10 & \\
\hline \multicolumn{3}{|l|}{ Age, years } & 0.007 \\
\hline Range & 25 to $\geq 65$ & 25 to $\geq 65$ & \\
\hline $18-24$ & $0(0)$ & $0(0)$ & \\
\hline $25-34$ & $50(36.0)$ & $60(56.1)$ & \\
\hline $35-44$ & $30(21.6)$ & $23(21.5)$ & \\
\hline $45-54$ & $24(17.3)$ & $13(12.2)$ & \\
\hline $55-64$ & $18(12.9)$ & $7(6.5)$ & \\
\hline$\geq 65$ & $17(12.2)$ & $4(3.7)$ & \\
\hline Missing* & 8 & 10 & \\
\hline \multicolumn{3}{|l|}{ Career status, no. $(\%)$} & $<0.001$ \\
\hline $\begin{array}{l}\text { Practicing family } \\
\text { physician }\end{array}$ & $71(50.7)$ & $27(25.2)$ & \\
\hline Full-time faculty & $31(22.2)$ & $25(23.4)$ & \\
\hline Resident-physician & $36(25.7)$ & $55(51.4)$ & \\
\hline Fellow & 0 & 0 & \\
\hline Other & $2(1.4)$ & 0 & \\
\hline Missing* & 7 & 10 & \\
\hline \multicolumn{4}{|l|}{ Years in practice, no. } \\
\hline Range & $\begin{array}{c}5 \text { months to } 44 \\
\text { years }\end{array}$ & 3 to 38 years & \\
\hline Mean (SD) & $18(12.4)$ & $21(10.9)$ & 0.004 \\
\hline \multicolumn{4}{|c|}{ Years as a full-time faculty, no. } \\
\hline Range & $\begin{array}{c}4 \text { months to } 31 \\
\text { years }\end{array}$ & $\begin{array}{c}2 \text { months to } 22 \\
\text { years }\end{array}$ & \\
\hline Mean (SD) & $13(10.4)$ & $8.2(6.6)$ & 0.040 \\
\hline \multicolumn{4}{|c|}{ Medical trainees, no. (\%) } \\
\hline $\begin{array}{l}\text { First-year } \\
\text { residents }\end{array}$ & $10(27.8)$ & $18(32.7)$ & \\
\hline $\begin{array}{l}\text { Second-year } \\
\text { residents }\end{array}$ & $12(33.3)$ & $20(36.4)$ & \\
\hline $\begin{array}{l}\text { Third-year } \\
\text { residents }\end{array}$ & $14(38.9)$ & $17(30.9)$ & \\
\hline
\end{tabular}

$\mathrm{SD}=$ Standard deviation

*The number of family physicians who completed the survey but did not provide an answer to this specific question. Missing responses were excluded from the total before percentages were calculated. 
A Likelihood-Ratio test was conducted to evaluate the relationship between the family physicians' decisions to recommend e-cigarettes as tobacco use cessation products and the sources where they commonly obtained information regarding e-cigarettes. The variables were correlated significantly $\left(\chi^{2}[2, \mathrm{n}=137]=6.8 ; \mathrm{p}=0.012\right.$; Cramer's $\mathrm{V}=$ 0.36; Table 2a). Follow-up pairwise comparisons were conducted to evaluate the differences among the groups. Holmes sequential Bonferroni method was used to control for Type I error at 0.05 across all the comparisons. Significant pairwise difference was found between medical literature and news media (Table 2b). Family physicians were less likely to recommend e-cigarettes as tobacco use cessation products if they commonly received information regarding e-cigarettes from the medical literature compared to the news media.

To determine if there was a change between 2016 and 2019 respondents' perceived effectiveness of e-cigarettes as tobacco use cessation products, comparisons among the three effectiveness groups were conducted using a Fisher's exact test. The results revealed statistically significant differences among the groups (Figure 1). There was a reduction in the proportion ( $70.8 \%$ vs. $41.1 \%$ ) of respondents who perceived e-cigarettes as an ineffective tobacco use cessation tool from 2016 to 2019. Nearly $80 \%$ of the 2019 respondents reported that e-cigarettes were either ineffective or were ambivalent about e-cigarettes as an effective tobacco cessation tool.

Qualitative Results: Family Physicians who Recommended E-cigarettes. Of the 247 respondents in the 2019 survey, $13.6 \%$ reported they recommended e-cigarettes for tobacco use cessation. Two major themes with three sub-themes emerged as reasons: e-cigarettes serve as tobacco use cessation products and e-cigarettes are the lesser of two evils compared to combustible cigarettes (Table 3 ).

Qualitative Results: Family Physicians who did not Recommend E-cigarettes. Just over $86 \%$ of the 247 family physicians in the 2019 survey did not recommend e-cigarettes for tobacco use cessation. Six themes emerged from the analyses: lack of data to support effectiveness of e-cigarettes, e-cigarettes are just as bad as combustible cigarettes, e-cigarettes are not regulated or not approved by the United States Food and Drug Administration (FDA), better options are available, concerns about safety of e-cigarettes, and other reasons (Table 4).

\section{DISCUSSION}

Our study demonstrated a statistically significant increasing trend in recommending against e-cigarette use for tobacco use cessation among family physicians. Compared to 2016, family physicians in the 2019 survey were more likely to recommend against e-cigarettes for tobacco use cessation. Reasons against recommending e-cigarettes included lack of evidence regarding both efficacy and safety, as well as increased concern of harms. These trends are consistent with the 2019 outbreak of EVALI and recommendations from government and professional organizations, including the $\mathrm{CDC}$ and $\mathrm{AAFP}$, to continue to recommend evidence-based tobacco use cessation counseling methods and FDA-approved tobacco use cessation products over e-cigarettes.

In anticipation of a change in family physicians' recommendations due to recent safety concerns, physicians were surveyed regarding their sourcesofinformationaboute-cigarettes. Physicianswhorecommended against e-cigarettes were more likely to obtain information from the
KANSAS JOURNAL of MEDIC INE PERCEPTIONS OF E-CIGARETTES IN TOBACCO USE COUNSELING

continued.

medical literature compared to news media, whereas physicians who recommended e-cigarettes were more likely to obtain information from the news media. Likewise, several major medical journals published case series and reports regarding EVALI. ${ }^{16-19}$ One possible reason for the variance in recommending e-cigarettes by information from medical literature may have been either more knowledge or concern regarding the potential harms of e-cigarettes.

Ambiguity in opinions regarding e-cigarette efficacy was apparent in our study and was supported by the conflicting current state of evidence. Interestingly, our results showed that family physicians were ambivalent about e-cigarettes as an effective tobacco cessation tool, and the majority did not recommend them. Furthermore, while more than one-third of physicians who did not recommend e-cigarettes reported a lack of supporting evidence about their effectiveness as an underlying reason, nearly one-quarter of physicians who recommended e-cigarettes noted efficacy as a reason they supported use. These differences in opinion are mirrored in the medical literature and major organizations' recommendations. For example, a 2016 Cochrane review found limited, low quality evidence that e-cigarettes are effective for tobacco use cessation, but not more than nicotine replacement. ${ }^{20}$ More recent randomized controlled trials ( $\mathrm{RCTs}$ ) have shown contradictory results.

While a $2018 \mathrm{RCT}(\mathrm{N}=6,131)$ did not find e-cigarettes to be more effective than tobacco use cessation counseling or nicotine replacement, ${ }^{21}$ a 2019 RCT $(\mathrm{N}=844)$ showed e-cigarettes to be more effective than nicotine replacement for tobacco use cessation. ${ }^{22}$ However, among patients who quit tobacco, $80 \%$ (63 of 79) who used e-cigarettes were using them still at 52 weeks compared to only $9 \%$ (4 of 44 ) of the nicotine replacement group. ${ }^{2}$

Additional reasons for not recommending e-cigarettes included the belief that e-cigarettes are "just as bad" as combustible cigarettes. For example, one physician noted that "they [e-cigarettes] are not any safer. We do not know what is in them." Physicians also were concerned about harmful additives and lack of regulation by the FDA. Others reported the availability of better options, such as nicotine replacement, bupropion, and tobacco cessation counseling, which are consistent with recommendations from the AAFP and CDC.

The majority of physicians who recommended e-cigarettes cited the ability to titrate down, or taper nicotine as a reason for e-cigarettes as a cessation tool. This was a new finding compared to the 2016 study. While using e-cigarettes may be seen as a way to taper off of nicotine, the evidence noted above suggests the contrary. ${ }^{22,23}$ Additional reasons for recommending e-cigarettes were similar to the 2016 study, which included the belief that they are the "lesser of two evils" and a "second-line option" if the patient requests it or declines other options. E-cigarettes often are marketed as a healthier alternative to tobacco. ${ }^{24,25}$ While limited evidence suggested a reduction in exposure to tobaccorelated carcinogens and toxins among e-cigarette users, e-cigarettes also are known to contain harmful toxins, including flavoring associated with lung injury, volatile organic compounds, and carcinogens. ${ }^{26}$ 


\section{KANSAS JOURNAL of MEDICINE}

PERCEPTIONS OF E-CIGARETTES IN TOBACCO USE

COUNSELING

continued.

Table 2a. Relationship of respondents' common sources of information regarding adverse effects of e-cigarettes compared with e-cigarettes recommendation, 2019.

\begin{tabular}{|l|c|c|c|c|c|c|}
\hline & \multicolumn{2}{|c|}{ Recommending E-cigarettes } & & & \\
\hline Measures & Yes & No & Total & Pearson $\chi^{2}$ & p value & Cramer's $V$ \\
\hline $\begin{array}{l}\text { Sources of information, } \\
\text { no. (\%) }\end{array}$ & & & & 8.60 & 0.012 & 0.36 \\
\hline Medical literature & $8(12.9)$ & $54(87.1)$ & $62(100)$ & & & \\
\hline News media & $11(21.6)$ & $40(78.4)$ & $51(100)$ & & & \\
\hline Other sources & $5(20.8)$ & $19(19.2)$ & $24(100)$ & & & \\
\hline Total & $24(17.5)$ & $113(82.5)$ & $137(100)$ & & & \\
\hline
\end{tabular}

Table 2b. Results for pairwise comparison using the Holm Sequential Bonferroni method, 2019.

\begin{tabular}{|l|c|c|c|}
\hline Comparisons & Pearson $\boldsymbol{\chi 2}$ & p value $(\boldsymbol{\alpha})$ & Cramer's V \\
\hline Medical literature vs news media & $8.97^{*}$ & $0.011(0.017)$ & 0.38 \\
\hline Medical literature vs other sources & 3.26 & $0.037(0.025)$ & 0.13 \\
\hline News media vs other sources & 1.64 & $0.16(0.050)$ & 0.18 \\
\hline
\end{tabular}

${ }^{*} \mathrm{p}$ value $\leq \alpha$

- $2016=2019$

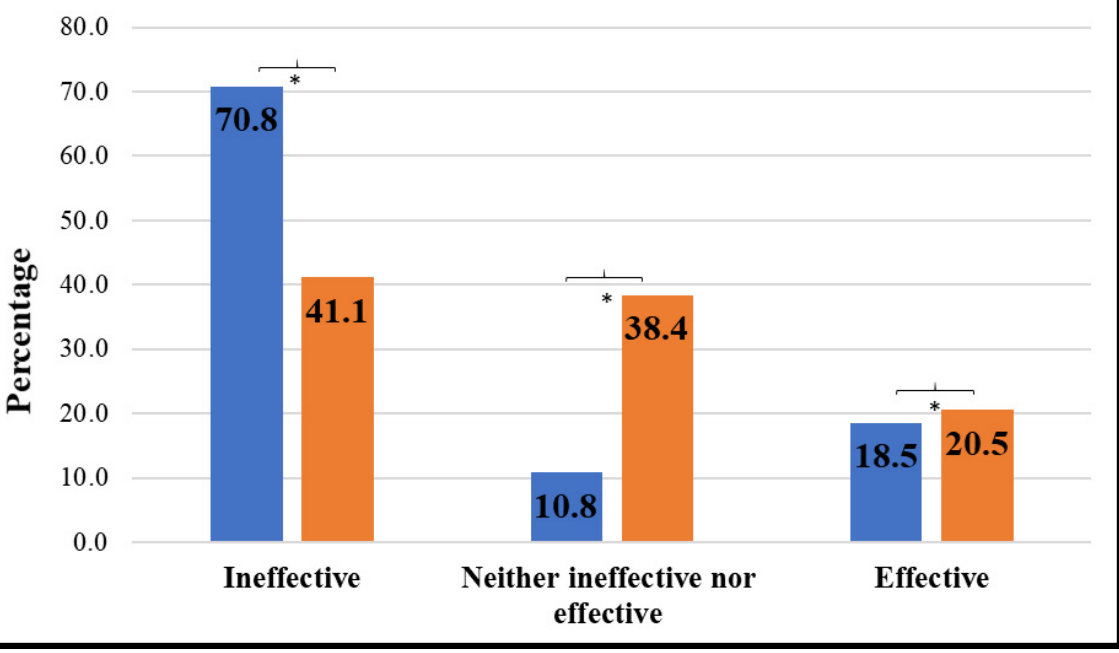

Figure 1. Family physicians' perceived effectiveness of electronic cigarettes in 2019 compared with 2016.

*Statistical difference

Table 3. Open-ended comments on reasons family physicians recommended e-cigarettes for tobacco use cessation, 2019 (Responses = 37).

\begin{tabular}{|c|c|c|}
\hline Themes & $\begin{array}{l}\text { Percentage of } \\
\text { Responses }\end{array}$ & Quotes from Participants \\
\hline \multicolumn{3}{|l|}{ E-cigarettes are tobacco use cessation products } \\
\hline \multirow{2}{*}{ Ability to titrate nicotine } & \multirow{2}{*}{$62 \%$} & "It can be a useful way to taper nicotine." \\
\hline & & "Provides an alternative until patient is ready to get off nicotine." \\
\hline \multirow[b]{2}{*}{ Effective smoking cessation products } & \multirow[b]{2}{*}{$23 \%$} & "The evidence supports increase success." \\
\hline & & $\begin{array}{l}\text { "Improve rates of smoking cessation. If used as recommended without flavor packs or other } \\
\text { additives." }\end{array}$ \\
\hline \multirow[t]{2}{*}{ Good second line option for smoking cessation } & \multirow[t]{2}{*}{$15 \%$} & $\begin{array}{l}\text { "Yes, but only if patients ask about it as an option to quit and with the caveat that it should only } \\
\text { be used as a cessation tool but not a substitute." }\end{array}$ \\
\hline & & "If the patient requests it. I offer it more if it's the only option the patient will consider." \\
\hline \multirow[b]{2}{*}{ Less risk/lesser of two evils } & \multirow[b]{2}{*}{$30 \%$} & [I] "generally believe they are less bad then real cigarettes." \\
\hline & & $\begin{array}{l}\text { "To reduce other family members exposure to secondhand smoke and as a way to taper } \\
\text { nicotine." }\end{array}$ \\
\hline
\end{tabular}


Table 4. Open-ended comments on reasons family physicians did not recommend e-cigarettes for tobacco use cessation, 2019 (Responses = 153).

\begin{tabular}{|c|c|c|}
\hline Themes & $\begin{array}{l}\text { Percentage of } \\
\text { Responses }\end{array}$ & Quotes for Participants \\
\hline \multirow{2}{*}{$\begin{array}{l}\text { Lack of data to support effectiveness of e- } \\
\text { cigarettes }\end{array}$} & \multirow[t]{2}{*}{$35 \%$} & $\begin{array}{l}\text { "Studies that show benefit are limited and there is no long-term data with effects } \\
\text { of the device." }\end{array}$ \\
\hline & & "Still very poor study data, likely still exposure to harmful chemicals." \\
\hline \multirow{2}{*}{$\begin{array}{l}\text { E-cigarettes are just as bad as combustible } \\
\text { cigarettes }\end{array}$} & \multirow{2}{*}{$30 \%$} & $\begin{array}{l}\text { "I feel they are just as bad for an individual's health and just as addictive as } \\
\text { cigarettes." }\end{array}$ \\
\hline & & "They are not any safer. We do not know what is in them." \\
\hline \multirow{2}{*}{ Lack of regulation/Not FDA approved } & \multirow{2}{*}{$11 \%$} & "Unregulated product with unknown long-term effects." \\
\hline & & "Flavor contents unregulated by the FDA, still a tobacco product." \\
\hline \multirow[b]{2}{*}{ Availability of better options } & \multirow[b]{2}{*}{$10 \%$} & $\begin{array}{l}\text { [I] "recommend other forms of treatment for nicotine withdrawal that don't } \\
\text { mimic the act of smoking." }\end{array}$ \\
\hline & & $\begin{array}{l}\text { "Little experience with e-cigarettes. Prefer to use other recommended resources } \\
\text { for smoking cessation such as NRT, Chantix, or bupropion, as well as Yes-800- } \\
\text { QUIT-NOW or Behavioral Health if interested." }\end{array}$ \\
\hline \multirow{2}{*}{ Safety concerns about the use of e-cigarettes } & \multirow{2}{*}{$10 \%$} & $\begin{array}{l}\text { "Recent evidence and case reports of lung disease and deaths associated with } \\
\text { e-cigs." }\end{array}$ \\
\hline & & $\begin{array}{l}\text { "Severe related lung injury documented recently and uncertain long-term side } \\
\text { effect profile." }\end{array}$ \\
\hline \multirow[t]{2}{*}{ Other reasons } & \multirow[t]{2}{*}{$4 \%$} & $\begin{array}{l}\text { "It's stupid. If you want to quit smoking why recommend another smoking ob- } \\
\text { ject to put more toxins. Why not just say use marijuana to quit cigarettes. Same } \\
\text { logic. Both stupid." }\end{array}$ \\
\hline & & $\begin{array}{l}\text { "I allow patients to use them to assist with quitting, but I don't suggest it to } \\
\text { them." }\end{array}$ \\
\hline
\end{tabular}

The 2019 survey had a higher proportion of older and currently practicing physicians compared to the 2016 survey, which included a higher proportion of resident physician respondents. In the 2016 study, being younger and a resident physician were associated with opposing e-cigarette use compared to more experienced community physicians. Despite having a greater proportion of community physicians in the 2019 study, there was an increasing trend to recommend against e-cigarettes for tobacco use cessation. This may be due to new evidence of significant potential harm from e-cigarettes including EVALI, as well as lack of consistent, high quality evidence that e-cigarettes are an effective tobacco cessation product. Additionally, it could be that resident physician respondents in the 2016 survey were now community physicians, thus opinions have not significantly changed.

Our study had several limitations. This survey presented a snapshot of family physicians' subjective responses about vaping. The results were limited to those community family physicians who were in active practice, as well as faculty and resident physicians of the three family medicine residencies sponsored by the KUSM$\mathrm{W}$ at the time of the study who chose to respond to the survey. Although several family physicians in Kansas were on the KUSM-W DFCM FM-RADIO list, the opinion of those who were not on the list could have changed the results of the study. Finally, due to the small sample size of our study, caution should be exercised in generalizing results to the larger medical community. Future, larger studies would be beneficial to further determine physicians' beliefs and practices regarding e-cigarettes as a tobacco use cessation tool.

\section{CONCLUSIONS}

Our study suggested that the majority of family physicians did not recommend e-cigarettes for tobacco cessation. There were varied opinions regarding efficacy and safety of e-cigarettes. These opinions were influenced by information source. Given recent safety concerns and lack of consistent evidence regarding efficacy of e-cigarettes, family physicians should consider recommending only current evidence-based smoking cessation methods to patients.

\section{REFERENCES}

${ }^{1}$ Schier JG, Meiman JG, Layden J, et al. Severe pulmonary disease associated with electronic-cigarette-product use - interim guidance. MMWR Morb Mortal Wkly Rep 2019; 68(36):787-790. PMID: 31513561.

${ }^{2}$ U.S. Department of Health and Human Services. CDC, FDA, States Continue to Investigate Severe Pulmonary Disease Among People Who Use E-cigarettes. September 13, 2019. https://www.cdc.gov/media/releases/2019/s082l-cdc-fda-states-e-cigarettes.html. Accessed on March 29, 2020 .

${ }^{3}$ Layden JE, Ghinai I, Pray I, et al. Pulmonary illness related to E-cigarette use in Illinois and Wisconsin - Final report. N Engl J Med 2020; 382(10):903-916. PMID: 31491072.

${ }^{4}$ U.S. Department of Health and Human Services. Outbreak of Lung Injury Associated with the Use of E-Cigarette, or Vaping, Products. Office on Smoking and Health, National Center for Chronic Disease Prevention and Health Promotion. Smoking and Tobacco Use. September 13, 2019. https:/ www.cdc.gov/tobacco/basic_information/e-cigarettes/severe-lung-disease. html. Accessed on March 29, 2020.

5 Sun LH, McGinley L. As vaping-related lung illnesses spike, investigators eye contaminants. The Washington Post. August 30, 2019. https://www.washingtonpost.com/health/as-vaping-related-lungillnesses-spike-investigators-eye-contaminants/2019/08/29/ cfe26032-ca78-11e9-be05-f76ac4ec618c_story.html?noredirect=on. Accessed March 30, 2020 


\section{KANSAS JOURNAL of MEDICINE}

PERCEPTIONS OF E-CIGARETTES INTOBACCO USE

\section{COUNSELING}

continued.

${ }^{6}$ Nedelman M. Cases of lung disease possibly linked to vaping continue to rise. This teen was given a 'second chance.' CNN Health. August 30, 2019. https://www.cnn.com/2019/08/30/health/vaping-lung-disease-texasteen/index.html. Accessed March 30, 2020.

7 Corum J. Vaping Illness Tracker: 2,602 Cases and 59 Deaths. The New York Times. January 13, 2020. https://www.nytimes.com/interactive/2020/ health/vaping-illness-tracker-evali.html. Accessed March 30, 2020.

${ }^{8}$ Stempniak M. Vaping-related deaths climb to 60, including youngest victim yet, as CDC finds strong THC link. Radiology Business. January 20, 2020. https://www.radiologybusiness.com/topics/care-delivery/vapingrelated-deaths-climb-60-including-youngest-victim-yet-cdc-finds-strong. Accessed March 30, 2020.

9 Alexander LEC, Perez MF. Identifying, tracking, and treating lung injury associated with e-cigarettes or vaping. Lancet 2019;394(10214):2041-2043. PMID: 31711628.

${ }^{10}$ Maessen GC, Wijnhoven RL, Neijzen RL, et al. Nicotine intoxication by e-cigarette liquids: A study of case reports and pathophysiology. Clin Toxicol (Phila) 2020; 58(1):1-8. PMID: 31286797.

11 Treitl D, Solomn R, Davare DL, Sanchez R, Kiffin C. Full and partial thickness burns from spontaneous combustion of e-cigarette lithium batteries with review of literature. J Emerg Med 2017; 53(1):121-125. PMID: 28501385.

12 Ofei-Dodoo S, Kellerman R, Nilsen K, Nutting R, Lewis D. Family physicians' perceptions of electronic cigarettes in tobacco use counseling. J Am Board Fam Med 2017; 30(4):448-459. PMID: 28720626.

${ }^{13}$ Creswell JW. Mapping the developing landscape of mixed methods research. In: Tashakkori A, Teddlie C. (Eds.) Sage Handbook of Mixed Methods in Social \& Behavioral Research. 2nd Edition. Thousand Oaks, CA: Sage, 2010, pp. 45-68. ISBN: 9781412972666.

${ }_{14}$ Ofei-Dodoo S, Callaway P, Engels K. Prevalence and etiology of burnout in a community-based graduate medical education system: A mixed-methods study. Fam Med 2019; 51(9):766-771. PMID: 31596935.

${ }_{15}$ Miller WL, Crabtree BF. Clinical Research. In: Denzin NK, Lincoln YS (Eds.) Handbook of Qualitative Research. Thousand Oaks, CA: Sage, 1994, pp. 340-352. ISBN: 1483349802.

${ }^{16}$ Cherian SV, Kumar A, Estrada-Y-Martin RM. E-cigarette or vapingproduct associated lung injury: A review. Am J Med 2020; 133(6):657-663. PMID: 32179055.

17 Billa R, Tigges C, Vijayakumar N, et al. E-Cigarette, or vaping, product use associated lung injury (EVALI) with acute respiratory failure in three adolescent patients: A clinical timeline, treatment, and product analysis. J Med Toxicol 2020; 16(3):248-254. PMID: 32193828.

18 Ahmad M, Aftab G, Rehman S, Frenia D. Long-term impact of e-cigarette and vaping product use-associated lung injury on diffusing capacity for carbon monoxide values: A case series. Cureus 2020; 12(2):e7002. PMID: 32206466.

19 Marlière C, De Greef J, Gohy S, et al. Fatal e-cigarette or vaping associated lung injury (EVALI): A first case report in Europe. Eur Respir J 2020; 2000077. PMID: 32217651.

${ }^{20}$ Hartmann-Boyce J, McRobbie H, Bullen C, Begh R, Stead LF, Hajek P. Electronic cigarettes for smoking cessation. Cochrane Database Syst Rev 2016; 9(9):CD010216. PMID: 27622384.

${ }^{21}$ Halpern SD, Harhay MO, Saulsgiver K, Brophy C, Troxel AB, Volpp KG. A pragmatic trial of e-cigarettes, incentives, and drugs for smoking cessation. N Engl J Med 2018; 378(24):2302-2310. PMID: 29791259.

${ }^{22}$ Hajek P, Phillips-Waller A, Przulj D, et al.A randomized trial of e-cigarettes versus nicotine-replacement therapy. N Engl J Med 2019; 380(7):629-637. PMID: 30699054.

${ }^{23}$ Kandra KL, Ranney LM, Lee JG, Goldstein AO. Physicians' attitudes and use of e-cigarettes as cessation devices, North Carolina, 2013. PLoS One 2014; 9(7):el03462. PMID: 25072466.

${ }^{24}$ Smith L, Brar K, Srinivasan K, Enja M, Lippmann S. E-cigarettes: How "safe" are they? J Fam Pract 2016; 65(6):380-385. PMID: 27474819.

${ }^{25}$ Kitzen JM, McConaha JL, Bookser ML, Pergolizzi JV Jr, Taylor R Jr, Raffa RB. e-Cigarettes for smoking cessation: Do they deliver? J Clin Pharm Ther 2019; 44(4):650-655. PMID: 30950094.
${ }^{26}$ National Academies of Sciences, Engineering, and Medicine; Health and Medicine Division; Board on Population Health and Public Health Practice; Eaton DL, Kwan LY, Stratton K, et al. Public Health Consequences of E-Cigarettes. Washington (DC): National Academies Press (US), 2018. PMID: 29894118.

Keywords: electronic cigarettes, family physician, lung injury, tobacco use cessation, Kansas 
The following set of questions seeks to assess your opinion regarding recommending electronic cigarettes to patients who smoke.

1. Do you recommend electronic cigarettes for smoking cessation?

a. Yes

b. No

Why or why not?

2. Would you recommend electronic cigarettes to a patient who cannot, or does not, want to stop smoking?

a. Yes

b. No

Why or why not?

3. Have you ever recommended electronic cigarettes for smoking cessation?

a. Yes

b. No

Why or why not?

4. In your opinion, how effective are electronic cigarettes in helping smokers to quit?
a. Very effective
b. Effective
c. Neither effective nor ineffective
d. Ineffective
e. Very ineffective

5 . Where do you most commonly receive information about adverse effects of electronic cigarettes?
a. Medical literature
b. News Media
c. Social Media
d. Colleagues
e. Other (please specify)

6. What is your current age? (Please select the range into which your age falls)
a. 18 - 24 years
b. 25 - 34 years
c. $35-44$ years
d. $45-54$ years
e. 55 - 64 years
f. $\geq 65$ years

7. What is your Gender? (Please select one)
a. Male
b. Female
c. Other (please specify)

8. I'ma...
a. Full time practicing family physician
b. Full time faculty
c. Resident-physician
d. Fellow
e. Other (please specify)

9. What is the number of years since you graduated from residency?

10. How long have you been a faculty physician?

11. What is your current year in residency?
a. PGY 1
b. PGY 2
c. PGY 3

Thank you for participating! 